\title{
Students' Learned Helplessness and Teachers' Care in EFL Classrooms
}

\author{
Hua He* \\ School of Foreign Languages, Zhengzhou Normal University, Zhengzhou, China
}

The construct of learned helplessness, as one of the noticeable emotional issues in education, has been investigated and approved its prominent place in education for its stimulus on students' accomplishment, enthusiasm, and commitment in learning. Moreover, the role of teachers as the most crucial issues in the learning viewpoint is at the center of attention since they help learners to be more motivated and provide a supportive context by caring. So, the current review of literature tries to emphasize teachers' care and its effects on decreasing learned helplessness in EFL classrooms. The review of this study underscores the important role of the teachers' care and support in learners' improvement of learned helplessness that can be alleviated in this way. Afterward, some suggestions are offered to illuminate the exercise of teachers, learners, teacher trainers, and syllabus designers.

\section{OPEN ACCESS}

Edited by:

Ali Derakhshan,

Golestan University, Iran

Reviewed by:

Ehsan Rezvani,

Islamic Azad University, Isfahan, Iran

Liu Wei,

Xinyang Normal University, China

*Correspondence:

Hua He

hehua@zznu.edu.cn

Specialty section:

This article was submitted to

Educational Psychology,

a section of the journal

Frontiers in Psychology

Received: 01 November 2021 Accepted: 26 November 2021

Published: 15 December 2021

Citation:

He H (2021) Students' Learned Helplessness and Teachers' Care in

EFL Classrooms.

Front. Psychol. 12:806587. doi: 10.3389/fpsyg.2021.806587
Keywords: EFL classrooms, students' learned helplessness, educational self-efficacy, EFL (English as a foreign language) learning, teachers' care

\section{INTRODUCTION}

Foreign language learners are all aware of the significance of attaining good English abilities, but some strike as not being motivated in the educational cycle. Their absence of interest in their participation is an example of discouragement which will subsequently lead to depression and demotivation (Hsu, 2011). Mostly, being scared of failing, being irresponsible, and escaping from completing tasks could result in failures (Sorrenti et al., 2004). Teachers have a hard time identifying the reasons for learners' failure or absence of perseverance in assignments, which affects learners' learned helplessness (LH) (Gordon and Gordon, 2006). Failure is bound to happen in any educational cycle. Nevertheless, what puts an end to education is not failure but the students' response to it, which happens to also mold their education (Daggol, 2018). Attributions are the grounds for individuals' achievements or failures when performing a specific assignment and regular attributes in a scholastic environment include endeavor, innate capability or intellectual capacity, difficult assignments, educators' support, and individual help (Horner and Gaither, 2004). Learners do not have real courage to solve issues and deal with difficulties, and they lack persistence and they tackle most assignments with a deconstructive behavior, an absence of inspiration, and inherent emotions of failure as well as incompetence (Wurm, 2021). These learners would rather ignore doing assignments or carry out simpler ones; therefore, they would not face disappointments that are regarded as a reflection of their innate absence of abilities. Moreover, when learners lack the capability of changing their reaction to difficult circumstances like coping with frustration and repetitive failures, and an essential inspiration or self-determination, they are then mentally evasive and possess LH (Eldowah and Alnajashi, 2017). They are incapable of altering or provoking the strategy fulfilled after their failure. Therefore, they ascribe no worth to their dedication, as they believe that they have no control over their educational cycle and 
their scholastic achievement (Dickhäuser et al., 2011). Students are at a danger of contracting LH when they face an academic failure cycle and they become less aware of their skills (Pasta et al., 2013). Consequently, such learners demonstrate a deconstructive attitude toward academic assignments, cease to be involved, and develop destructive feelings like frustration and stress (Filippello et al., 2018). Learned helplessness is an outcome of recurrent perception that the result of a certain stressful circumstance has nothing to do with the practice of a person in that circumstance (Peterson, 2010). The LH mindset can ultimately have serious deconstructive effects on a person in which extreme levels of $\mathrm{LH}$ create self-abandonment in learners and the mental discomfort resulting from LH leads to feeling lost, mentally void, depressed in students, and ultimately develop false views on values and life ( $\mathrm{Wu}$ and $\mathrm{Tu}, 2019$ ). It is not solely their attitudes that are self-destructive; rather the ones with them experience similar feelings when it comes to getting the job done and confronting hardships. When learners graduate, these practices and attitudes do not suddenly disappear, rather they affect their life after graduation, and it is passed on to adulthood, work-life, social life, and psychological well-being (Wurm, 2021). Out of the elements that have an important function in this field, Carson et al. (2002) connected LPs with educators' practices because the learners who were not supervised by the educator were essentially helpless. while strict teaching behaviors like mental control can contribute to anxiety and poor psychological wellbeing, the self-determination theory (SDT) proposed that care from others like parents and educators is crucial for learners' achievement (Ryan and Deci, 2017). Moreover, student-educator interactions are significant in different domains that can greatly affect a learner's development and growth and as a matter of fact, self-esteem is more likely to occur when learners feel that they are actively supported by their class educators (Jones and Hensley, 2012; Xie and Derakhshan, 2021). Indeed, the educator plays a role in a classroom's success in language education and their efficacy can affect learners' accomplishments or failures in education as Raufelder et al. (2013) discovered that learners at school who were self-aware, experienced less LH because they had a better connection with their educators. Learners' conceptions of educator's care illustrate significant aspects of learner-educators associations (Wentzel, 2016). Teachers' care inspires learner-related competencies like commitment, selfassurance, well-being, and success (Derakhshan et al., 2019; Sun, 2021). Moreover, the students who are cared for by their educators are exposed to a low level of LH as a result educators should have healthy relationships that care about their students in diverse circumstances which hinder their LH (Wang and Eccles, 2012).

Additionally, LH impedes educational success (Filippello et al., 2020), so, on the one hand, ignoring or not paying attention to $\mathrm{LH}$ in foreign language education contribute to worse outcomes since such learners affect others and influence identical practices (Sucu and Bulut, 2019) and on the other hand, adequate attention has not been paid to $\mathrm{LH}$ in the scholastic setting and this is likely due to it not being identified by educators as a state that could bring about grave issues in learners, like depression (Filippello et al., 2018). Remaining in this LH condition can leave the person less inspired to carry out new practices for the sake of dealing with deconstructive occurrences, being overwhelmed by a feeling of frustration that is closely associated with depression and stress (Filippello et al., 2018). The most difficult and distressing aspect of educators' experience was caring about learners who slowly lose their interest in English education and became LH. So by evaluating associated research on learned helplessness, founded on the scholar's information, numerous investigations solely emphasized the influences of educational self-efficacy on learned helplessness as well as the influence of educators' anticipations on learned helplessness in general education (Putwain and Symes, 2014; Wu and Tu, 2019) and, the role of teachers' care has not been much investigated in EFL context so far. Therefore, the present review aimed to fill this gap by inspecting the function of teachers' care on students' $\mathrm{LH}$ in EFL classrooms.

\section{REVIEW OF LITERATURE}

\section{Learned Helplessness}

Learned helplessness can be explained as an intricate layout of flawed attributions that have been actualized as fundamental to a cognitive-behavioral hypothesis of dissatisfaction and that can also assist with clarifying some behavioral issues like a weak academic achievement (Schleider et al., 2014). In addition, LH is a mental condition defined by an inner, fixed, and international style of attribution for failures; an exterior, unsteady, and particular attribution style for success; absence of self-confidence in one's skills and intellect; interpretation prejudice of occurrences; and deconstructive prediction of achievements (Filippello et al., 2020) and it refers to an impediment learners face in language education as Hall et al. (2008) regard it as a mental state that causes people to think they have lost control of an adverse circumstance, that their actions are pointless, and that they are defenseless. Also, LH has been described by Saxena and Shah (2008) as a mental state in which animals or humans cannot control the ineffectiveness of their endeavors and they maintained that this type of belief is followed by becoming passive even when exposed to detrimental or deconstructive circumstances. In the school context, LH is a cycle oriented toward dominance on the one hand and helplessness on the other hand; consequently, learned helpless people demonstrate less perseverance in the assignment as well as a lower will to succeed when the assignment seems difficult (Odabasi, 2013).

\section{Teachers' Care}

As stated by Mayseless (2015), caring is a feeling, an attachment, and a behavioral demonstration that surrounds all human beings and can be explicated as an emotion, an inspiration, and/or a practice, mirroring worries about the emotions and demands of others. For a safe and viable educator-learner association, educators' care is a significant element that can add to a learner's growth (Lavy and Naama-Ghanayim, 2020; Wang and Guan, 2020). Caring and emotionally comforting associations with educators are especially significant for undervalued outnumbered learners and English students that is one of the 
mechanisms of safe, current educator-learner rapport, which can be effective in learners' progress. Educators' caring is an intricate concept that involves hearing out and being interested in what learners would like to relay, considering their emotions, developing trust, and assisting them with attaining their optimum capacity (Noddings, 2012).

\section{IMPLICATIONS AND FUTURE DIRECTIONS}

Learned helplessness is a construct created mainly in psychology and is intertwined with numerous other notions, all of which are demonstrated to learners through teaching. With the help of the literature review, it becomes clear that there are many ways in which teachers can help their learners reach their highest potential. So this review can add to the literature by confirming the key function of the educator in caring about LH students' accomplishment. Although students learn specific practices and attitudes during their education, there are methods educators can apply to assist learners with reducing $\mathrm{LH}$ and creating resilience. Educators need to help learners with observing their endeavors' effects on their achievement, rather than their talents or incompetence. The current review underlines the nature of educators' care and their emotional comfort like their kindness or reception to learners' demands can keep students away from developing deconstructive relational results. Through teacher care, social ties are created between teachers and learners in which the learners feel appreciated and encouraged leading to students' motivation and persistence that consequently decrease their LH.

Along with the prominence of academic improvements in the EFL setting, educators should devote more time to constructing caring behavior that increases their self-efficacy, promotes their language education, and lessens or even prevents their $\mathrm{LH}$. Indeed, educators are advised to recognize helpless learners and take them for granted and be careful to avoid comparing them to one another or avoid creating settings that foster competition. Moreover, some approaches are endorsed to be utilized in the classroom that would motivate helpless learners to challenge themselves. In this way, the content developed by the syllabus designers should be motivating enough which trigger their interests.

Failure is an expected issue in the process of learning; nevertheless, it is not failure that stops education, then again it is student's response to failure that forms his/her learning that leads learners to gradually lose attentiveness in learning and develop their LH and to lessen the degree of LH in English education, learners must be helped with developing suitable goals when it comes to learning English and this happens with educators' guidance. When learners perceive that their educator pays attention to them, they develop greater self-assurance and a constructive educator-learner association is created at school, which leads to a lower degree of LH at school. Learners' feeling that their educator cares for them is probable to promote the level of learners' trust and constructive feeling toward the learners and trust was interconnected to start a positive relationship with teachers and caring has been deemed a basis for an encouraging their relationship that encompasses a significant construction which permits educators to accomplish the learners' desires with empathy and warmth (Mayseless, 2015). With the help of adequate levels of educator's care, learners are capable of becoming more autonomous and positive concerning their scholastics and this shows that deconstructive attributions for achievement and failure can be substituted to decrease LH. A great degree of emotional comfort from educators kept learners with high degrees of scholastic disengagement.

Educator training must consider the impacts of caring educators on learners and create plans that strengthen educator caring capabilities and aware educators of its potential influences and possible antecedents. To strengthen their responsiveness to learners' feelings and to react positively to their emotional demands, educators must be educated as it appears that developing a constructive educator-learner is a precondition for enhancing scholastic achievement. Furthermore, direct interference is necessary because neglecting learners' helpless practices, in the long run, can render them unreactive or late reactive. Also, the participation of learners in a self-inspired manner must be enhanced with the help of controlling their objectives and anticipations. As LH is an important concept, more research must be conducted from various dimensions, and more interference ought to be made to decrease the $\mathrm{LH}$ in English education. Studies should be led to observe the optimum methodologies for overcoming $\mathrm{LH}$ that is regarded as extreme and expand over numerous settings.

\section{AUTHOR CONTRIBUTIONS}

The author confirms being the sole contributor of this work and has approved it for publication.

\section{FUNDING}

This study was supported by Humanities and Social Science Project (Youth Project) administered by the Education Department of Henan Province in 2021-Research on the Training of University Normal Students Based on British CELTA Concept (No.: 2021-ZZJH-480).

\section{REFERENCES}

Carson, D., Chowdhury, A., Choudhury, R., and Carson, C. (2002). Competence and family support of vulnerable and invulnerable adolescents representing scheduled tribes and castes in India. J. Comparat. Fam. Stud. 33, 249-270. doi: $10.3138 /$ jcfs.33.2.249

Daggol, G. D. (2018). An examination of Turkish college-level students' learned helplessness states in EFL context. Yüksekögretim ve Bilim Dergisi 1, 145-161. doi: $10.5961 /$ jhes.2018.257

Derakhshan, A., Saeidi, M., and Beheshti, F. (2019). The interplay between Iranian EFL teachers' conceptions of intelligence, care, feedback, and students' stroke. IUP J. Engl. Stud. 14, 81-98. 
Dickhäuser, O., Reinhard, M. A., and Englert, C. (2011). Of course, I will: the combined effect of certainty and level of expectancies on persistence and performance. Soc. Psychol. Educ. 14, 519-528. doi: 10.1007/s11218-011-9159-x

Eldowah, A. M., and Alnajashi, S. A. (2017). The effectiveness of a multidimensional teaching strategy on students' attitudes and level of learnedhelplessness. Int. J. Psychol. Stud. 9, 1-11. doi: 10.5539/ijps.v9n3p1

Filippello, P., Buzzai, C., Costa, S., Orecchio, S., and Sorrenti, L. (2020). Teaching style and academic achievement: the mediating role of learned helplessness and mastery orientation. Psychol. Schools 57, 5-16. doi: 10.1002/pits.22315

Filippello, P., Harrington, N., Costa, S., Buzzai, C., and Sorrenti, L. (2018). Perceived parental psychological control and school learned helplessness: the role of frustration intolerance as a mediator factor. School Psychol. Int. 39, 360-377. doi: 10.1177/0143034318775140

Gordon, R., and Gordon, M. (2006). The Turned Off Child: Learned Helplessness and School Failure. Salt Lake City, UT: Millennial Mind Publishing.

Hall, C., Goodwin, D., Heleski, C., Randle, H., and Waran, N. (2008). Is there evidence of learned helplessness in horses? J. Appl. Anim. Welfare Sci. 11, 249-266. doi: 10.1080/10888700802101130

Horner, S. L., and Gaither, S. M. (2004). Attribution retraining instruction with a second-grade class. Early Childh. Educ. J. 31, 165-170. doi: 10.1023/B:ECEJ.0000012134.58050.2a

Hsu, L. (2011). A qualitative analysis on the occurrence of learned helplessness among EFL students. J. Educ. Dev. Psychol. 1, 162-175. doi: $10.5539 /$ jedp.v1n1p162

Jones, J. L., and Hensley, L. R. (2012). Taking a closer look at the impact of classroom placement: students share their perspective from inside special education classroom. Educ. Res. Quart. 35, 33-49.

Lavy, S., and Naama-Ghanayim, E. (2020). Why care about caring? Linking teachers' caring and sense of meaning at work with students' selfesteem, well-being, and school engagement. Teach. Teacher Educ. 91, 1-12. doi: $10.1016 /$ j.tate. 2020.103046

Mayseless, O. (2015). The Caring Motivation: An Integrated Theory. Oxford: Oxford University Press. doi: 10.1093/acprof:oso/9780199913619.001.0001

Noddings, N. (2012). The caring relation in teaching. Oxford Rev. Educ. 38, 771-781. doi: 10.1080/03054985.2012.745047

Odabasi, B. (2013). The effect of learned helplessness to the success. Int. J. Acad. Res. 5, 125-133. doi: 10.7813/2075-4124.2013/5-4/B.18

Pasta, T., Mendola, M., Longobardi, C., Prino, L. E., and Gastaldi, F. G. M. (2013). Attributional style of children with and without a specific learning disability. Electr. J. Res. Educ. Psychol. 11, 649-655. doi: 10.14204/ejrep.31.13064

Peterson, C. (2010). Learned Helplessness. Hoboken, NJ: Wiley Online Library. doi: 10.1002/9780470479216.corpsy0500

Putwain, D. W., and Symes, W. (2014). The perceived value of maths and academic self-efficacy in the appraisal of fear appeals used prior to a highstakes test as threatening or challenging. Soc. Psychol. Educ. 17, 229-248. doi: 10.1007/s11218-014-9249-7

Raufelder, D., Drury, K., Jagenow, D., Hoferichter, F., and Bukowski, W. (2013). Development and validation of the relationship and motivation scales to assess students' perceptions of peers and teachers as motivators in adolescence. Learn. Individ. Differ. 24, 182-189. doi: 10.1016/j.lindif.2013.01.001

Ryan, R. M., and Deci, E. L. (2017). Self-Determination Theory: Basic Psychological Needs in Motivation, Development, and Wellness. New York, NY: Guilford. doi: $10.1521 / 978.14625 / 28806$
Saxena, S., and Shah, H. (2008). Effect of organizational culture on creating learned helplessness attributions in R\&D professionals: a canonical correlation analysis. Vikalpa 33, 25-45. doi: 10.1177/025609092008 0203

Schleider, J. L., Ve’lez, C. E., Krause, E. D., and Gillham, J. (2014). Perceived psychological control and anxiety in early adolescents: the mediating role of attributional style. Cogn. Ther. Res. 38, 71-81. doi: 10.1007/s10608-013-9 573-9

Sorrenti, L., Larcan, R., Cuzzocrea, F., and Oliva, P. (2004). Influence of emotional aspects on academic performances. Int. J. Psychol. 39:136.

Sucu, H. O., and Bulut, M. (2019). "Investigating university preparatory students' level of learned helplessness in learning English in terms of different variables," in Chaos, Complexity and Leadership 2017. Springer Proceedings in Complexity, eds S. Erçetin and N. Potas (Cham: Springer), 587-605. doi: 10.1007/978-3-319-89875-9_49

Sun, Y. (2021). The effect of teacher caring behavior and teacher praise on students' engagement in EFL classrooms. Front. Psychol. 12:746871. doi: $10.3389 /$ fpsyg.2021.746871

Wang, M. T., and Eccles, J. S. (2012). Social support matters: longitudinal effects of social support on three dimensions of school engagement from middle to high school. Child Dev. 83, 877-895. doi: 10.1111/j.1467-8624.2012.01745.x

Wang, Y. L., and Guan, H. F. (2020). Exploring demotivation factors of Chinese learners of English as a foreign language based on positive psychology. Revista Argentina de Clinica Psicologica. 29, 851-861.

Wentzel, K. R. (2016). “Teacher-student relationships," in Handbook of Motivation at School, eds K. R. Wentzel and D. B. Miele (New York, NY: Routledge), 211-230. doi: 10.4324/9781315773384

Wu, S., and Tu, C. C. (2019). The impact of learning self-efficacy on social support towards learned helplessness in China. EURASIA J. Math. Sci. Technol. Educ. 15, 2-10. doi: 10.29333/ejmste/115457

Wurm, L. (2021). Effective teaching approaches to combat learned helplessness for students in high school special education. Culminating Projects Spec. Educ. 104

Xie, F., and Derakhshan, A. (2021). A conceptual review of positive teacher interpersonal communication behaviors in the instructional context. Front. Psychol. 12:2623. doi: 10.3389/fpsyg.2021.708490

Conflict of Interest: The author declares that the research was conducted in the absence of any commercial or financial relationships that could be construed as a potential conflict of interest.

Publisher's Note: All claims expressed in this article are solely those of the authors and do not necessarily represent those of their affiliated organizations, or those of the publisher, the editors and the reviewers. Any product that may be evaluated in this article, or claim that may be made by its manufacturer, is not guaranteed or endorsed by the publisher.

Copyright (c) $2021 \mathrm{He}$. This is an open-access article distributed under the terms of the Creative Commons Attribution License (CC BY). The use, distribution or reproduction in other forums is permitted, provided the original author $(s)$ and the copyright owner(s) are credited and that the original publication in this journal is cited, in accordance with accepted academic practice. No use, distribution or reproduction is permitted which does not comply with these terms. 